Karami E., Bardet S., Matsuo M., Brémaud I., Gaff M., Gril J. (2020) Effects of mild hygrothermal treatment on the physical and vibrational properties of spruce wood, Composite Structures 253 https://doi.org/10.1016/j.compstruct.2020.112736

\title{
Effects of mild hygrothermal treatment on the physical and vibrational properties of spruce wood
}

\author{
Elham KARAMI ${ }^{1,2}$, Sandrine BARDET ${ }^{1}$, Miyuki MATSUO ${ }^{3}$, Iris BREMAUD ${ }^{1}$, Milan Gaff ${ }^{2}$, Joseph GRIL ${ }^{1,4}$ \\ 1 LMGC, University Montpellier, CNRS, Montpellier, France \\ 2 Department of Wood Processing and Biomaterials, University CULS, Prague, Czech Republic \\ 3 Graduate School of Bio agricultural Sciences, Nagoya University, Japan \\ 4 Institut Pascal, Université Clermont Auvergne, CNRS, Sigma Clermont, Clermont-Ferrand, France
}

\begin{abstract}
Spruce wood specimens were treated under mild temperatures $130^{\circ} \mathrm{C}$ and $150^{\circ} \mathrm{C}$ and different relative humidity from $0 \%$ to $25 \%$. EMC reduced significantly for all the treatments. Weight loss (WL) increased insignificantly while the colour parameter, $\mathrm{L}^{*}$, decreased dramatically. Tan $\delta$ reduced significantly while the E/d has increased. After reconditioning, the partially reversibility has been achieved for $\mathrm{EMC}$, tan $\delta$ and $\mathrm{E} / \mathrm{d}$. But, still an irreversible changes remains, which suggested being due to the chemical changes in wood polymers. While reversible changes has been resulted from the annealing of amorphous polymers. Since, the mild hygrothermal treatment applied to the specimens coincided with no significant WL, there was no obvious damage in wood structure while the irreversible changes present an improvement in vibrational properties by decrease in damping $(\tan \delta)$, which could be due to the intermediate relative humidity of the treatment.
\end{abstract}

Keywords: mild treatments, weight loss, colour parameter, reversible effects, reconditioning, damping

\section{INTRODUCTION}

Thermal treatment of wood has been considered as an environmentally friendly modification method for improving the physical, mechanical and acoustical properties. A lot of research has been done on the properties of thermally modified wood $[1 ; 2 ; 3 ; 4 ; 5 ; 6 ; 7 ; 8 ; 9$; 10; 11; 12] (Kollmann, 1936; Stamm et Hansen, 1937; Kollmann et Schneider, 1963; Kollmann et Fengel, 1965; Militz, 2002; Obataya et Tomita, 2002; Tjeerdsma et Militz, 2005; Hill, 2006; Boonstra, 2008; Matsuo et al., 2010; Sandberg et Navi, 2011, Endo et al., 2015).

Thermal treatment improves dimensional stability by decreasing hygroscopicity, which is the most important effect of thermal modification of wood. Reduced wood hygroscopicity results in stabilizing mechanical and acoustic properties depending on moisture content.

Hygrothermal treatment can be considered as an artificial or accelerated aging by the elevated temperature. Noguchi et al. (2012) [13] mentioned that the improved stiffness and stability obtained through thermal treatment of wood leads to its consideration as "artificial aging" and an ecological method for the modification of new wood. 
The effects of thermal modification are partly recoverable by moistening depending on temperature and relative humidity of treatment. Obataya et Tomita (2002) [6] has investigated the reversible and irreversible reduction of hygroscopicity during mild hygrothermal treatment $\left(60-200^{\circ} \mathrm{C}\right)$. They suggested that the reversibility of variations of EMC were due to the rearrangement of amorphous molecules as they are mobilised during moistening at high relative humidity, while the temporary reduction was attributed to the annealing of amorphous molecules Also, the chemical changes in the lignin would be responsible for the irreversible changes of EMC. Another study by [14] Obataya et al (2000) has indicated that the irreversible reduction in hygroscopicity was due to the chemical change of amorphous polymers but not to the recrystallization of cellulose. Obataya (2017) [15] investigated the reversibility of physical and acoustical properties of natural and artificial aging and suggested that moistening causes partially reversibility for both natural and hygrothermally treated wood, especially at an intermediate relative humidity. Also, this study indicated that mild hygrothermal treatment improves the acoustical properties. Pfriem (2015) [16] suggested that the effects of mild hygrothermal treatment could be compared with artificial aging, based on measurable parameters of thermally modified wood such as dimensional stability and acoustical properties.

As weight loss (WL) is an indicator of the intensity of treatment, some study has been done to investigate WL and its correlation with mechanical and chemical changes for different treatment conditions. WL during hygrothermal treatment indicates some chemical changes in wood structure, which results in changes in material and colour of wood. Treatment at moderate temperature causes cleaves of acetyl groups of the hemicelluloses while treatment at high temperature results in reduction in accessibility of hydroxyl groups [7] (Tjeerdsma et Militz, 2005).

Kubojima et al (1998) [17] found that the damping coefficient ( $\tan \delta)$ of hygrothermally treated spruce wood decreased in an autoclave while using high relative humidity induced an increase in $\tan \delta$. Decrease in damping could be due to the structural change in wood polymer such as cross-linking of lignin [7] (Tjeerdsma et Militz, 2005). Another possible structural change response for reduced damping could be crystallization of cellulose [17] (Kubojima et al., 1998).

As thermal modification leads to structural changes in wood polymers, studying these changes is essential for understanding the basic effects of thermal modification. [18] Assor et al (2009) studied the changes in viscoelastic properties and amorphous polymers during the hydrothermal treatment. They have been treated Hardwood and softwood (oak and spruce) and mentioned that different wood species and treatment temperatures have different pattern of modifications.

A study by Froidevaux (2012) [19] suggested that mild thermal treatment, below $150^{\circ} \mathrm{C}$ but at a non-zero relative humidity resulted in chemical variations similar to the variations of naturally aged wood, with reduction of lightness.

Another interesting investigation has performed by Endo et al (2015) [12]. They have studied the effect of mild hygrothermal treatment at $120^{\circ} \mathrm{C}$ and various relative humidity on the properties of Sitka spruce. They have reported that mild hygrothermal treatment at an intermediate relative humidity resulted in decrease in tan $\delta$ and an increase in specific Young's modulus (E/d), while treatment at high relative humidity caused increase in tan $\delta$ and decrease in E/d . Their results have suggested that treatment in an intermediate relative humidity improve the acoustical properties. Nonetheless, the reversibility of hygrothermal treatment by moistening should be considered. 
The main problem with HTT is whether their effect on the different properties is reversible or not. Reversible effects can provoke changes in properties not because of the degradation of wood components, but because of stresses induced during treatments, which will be released after reconditioning.

In the present work, mild HTT have been applied to study the effects of accelerated aging of wood on the physical and mechanical properties. After a mild HTT, reconditioning has been applied. The purpose is to investigate the reversible or irreversible effects of HTT on the physical and mechanical properties of wood.

\section{Material and Methods}

\section{Material}

\section{Test samples}

This study was done on spruce (Picea abies (L) Karst.), as this species is the main material for soundboards of European classical string instruments. There were 30 specimens in longitudinal (L) direction (12 x $2.5 \times 150 \mathrm{~mm} 3, \mathrm{R} \times \mathrm{T} \times \mathrm{L})$ and 30 in radial (R) direction $(120 \mathrm{x}$ $2.5 \times 12 \mathrm{~mm} 3, \mathrm{R} \times \mathrm{T} \times \mathrm{L})$. They came from 3 trees, with L matching of specimens between 6 different groups. 5 groups were intended for 5 given modalities of treatment (Table 1) and 1 group remained untreated to serve as a control.

\section{Conditioning and control}

The samples, which had been naturally air-dried, were stored for at least 3 weeks in a climatic room $\left(20{ }^{\circ} \mathrm{C}\right.$ and $\left.65 \% \mathrm{RH}\right)$ in order to get stabilised at "standard air-dry" condition, which was the initial condition for the HTT of wood. The average moisture content was $12.4 \%$.

After treatment, equilibrium (still after at least 3 weeks at $20^{\circ} \mathrm{C}$ and $65 \% \mathrm{RH}$ ) was reached after oven drying. The difference between these two kinds of conditioning (before and after treatments) is taken into account in the results by subtracting the variations observed on control groups. Control specimens only underwent oven drying and reconditioning at $65 \% \mathrm{RH}$. The group of control specimens always underwent all the conditioning steps of the protocol shown below, but no treatment (hygrothermal nor recovery), and served to evaluate any experimental artefact in observed changes of properties.

\section{Methods}

\section{Steps of measurements}

After stabilization in climatic room (at $20^{\circ} \mathrm{C}$ and $65 \% \mathrm{RH}$ ), physical and vibrational properties were measured in the same room, as vibrational properties are highly dependent upon moisture content and its variations [20; 21] (Obataya et al. 1998, Brémaud and Gril 2015). Colorimetric values were also measured. Then, oven drying was carried out at $60^{\circ} \mathrm{C}$ for $24 \mathrm{~h}$ followed by $2 \mathrm{~h}$ at $103^{\circ} \mathrm{C}$. After oven drying, weight, dimensions and colorimetry were measured again. Then, treatments have been applied. For each treatment, intermediate data were measured every day for dimension, weight and colorimetery. Final values of these properties were also

measured at the end of each treatment. Then, specimens were stabilized again at $20^{\circ} \mathrm{C}$ and 
$65 \% \mathrm{RH}$ to compare untreated and treated physical and vibrational properties, and finally a cycle of humidity re-conditioning was applied before measuring the last values (see flow-chart in Fig. $1)$.

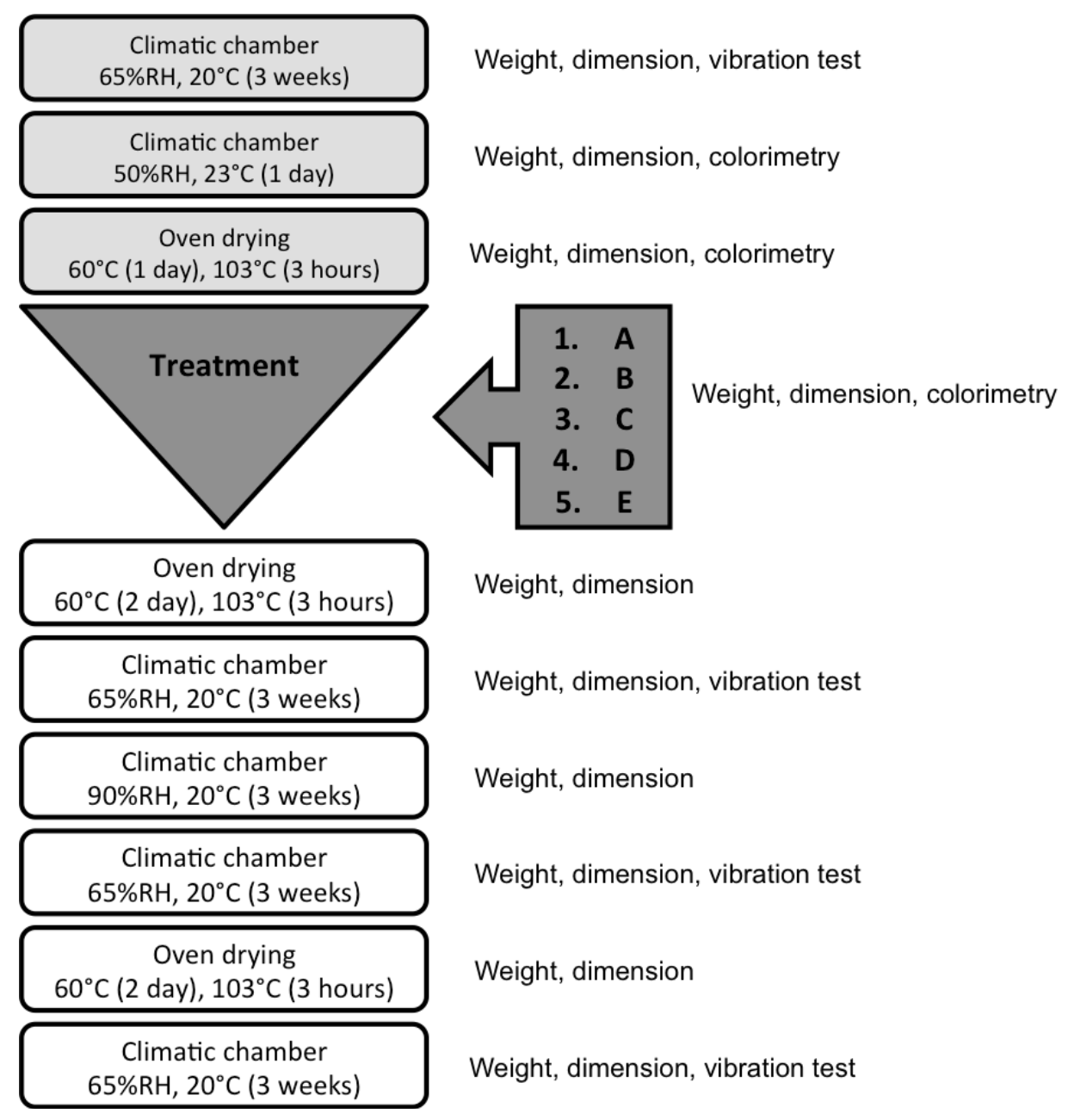

Fig. 1. Different steps of the process: $\mathrm{T}^{\circ} \mathrm{C}$ and $\mathrm{RH}$ conditions, treatments applied and measurements.

\section{Hygro-thermal treatments}

After primary measurements, specimens were exposed to hygro-thermal treatments (HTT). Two automatic thermo-hydrous reactors have been used (by RINO Sàrl, Blonay, Switzerland). Five different HTT were applied (Table 1). At $130^{\circ} \mathrm{C}$, two different treatments were applied to two different groups: $0 \% \mathrm{RH}$ (treatment $\mathrm{A}$ ) and variable humidity between 0 and $25 \% \mathrm{RH}$ (treatment B). At $150^{\circ} \mathrm{C}, 3$ conditions were applied: constant $0 \% \mathrm{RH}$ (treatment $\mathrm{C}$ ), variable humidity by steps or oscillations between 0 and $25 \% \mathrm{RH}$ (treatments $\mathrm{D}$ and $\mathrm{E}$ ). The whole history of relative humidity was recorded for each treatment (Fig. 2) and could be implemented in modelling.

Table 1. Conditions of treatments

\begin{tabular}{cccc}
\hline Treatments & $\begin{array}{c}\text { Relative } \\
\text { humidity }\end{array}$ & Temperature & Duration \\
\hline A & Constant, $0 \%$ & $130^{\circ} \mathrm{C}$ & 7 days
\end{tabular}




\begin{tabular}{cccc} 
B & Varying, $0-25 \%$ & $130^{\circ} \mathrm{C}$ & 7 days \\
C & Constant, $0 \%$ & $150^{\circ} \mathrm{C}$ & 7 days \\
D & $0-25 \%$ & $150^{\circ} \mathrm{C}$ & 4 days \\
E & $0-25 \%$ & $150^{\circ} \mathrm{C}$ & 3 days \\
\hline
\end{tabular}

(a) Treatment B

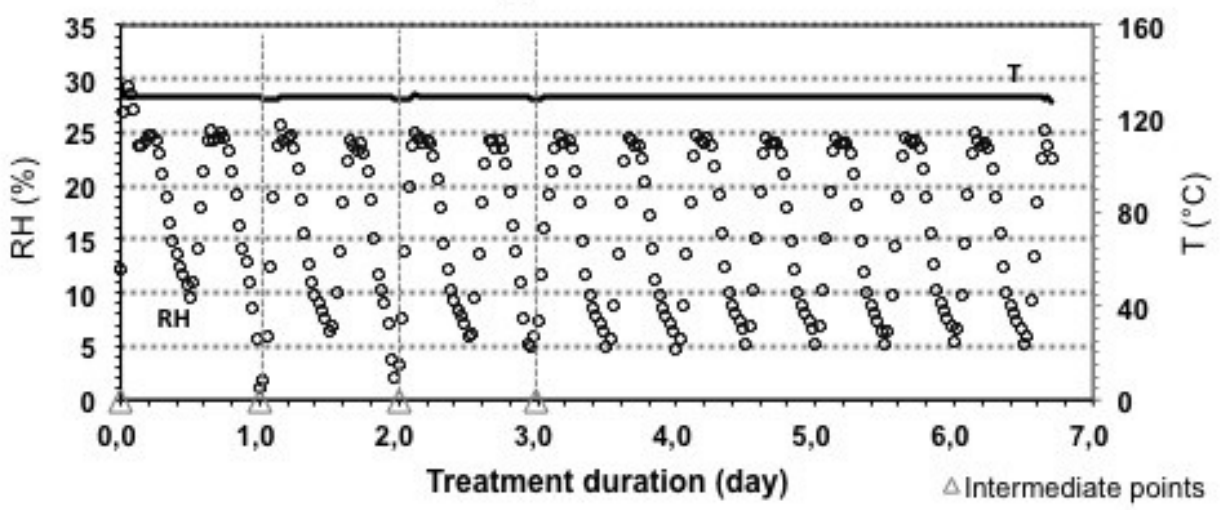

(b) Treatment D

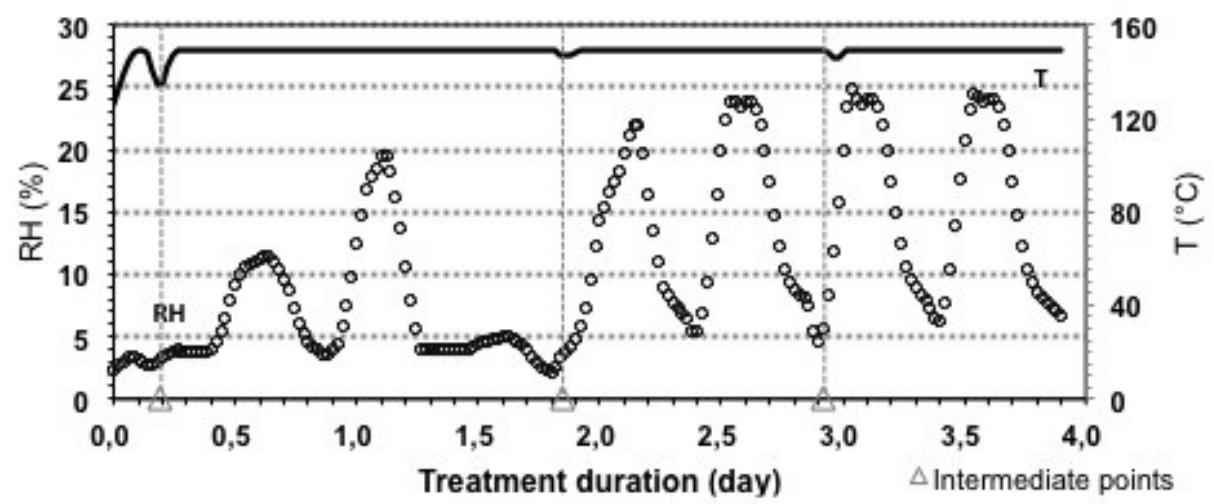

(c) Treatment $\mathrm{E}$

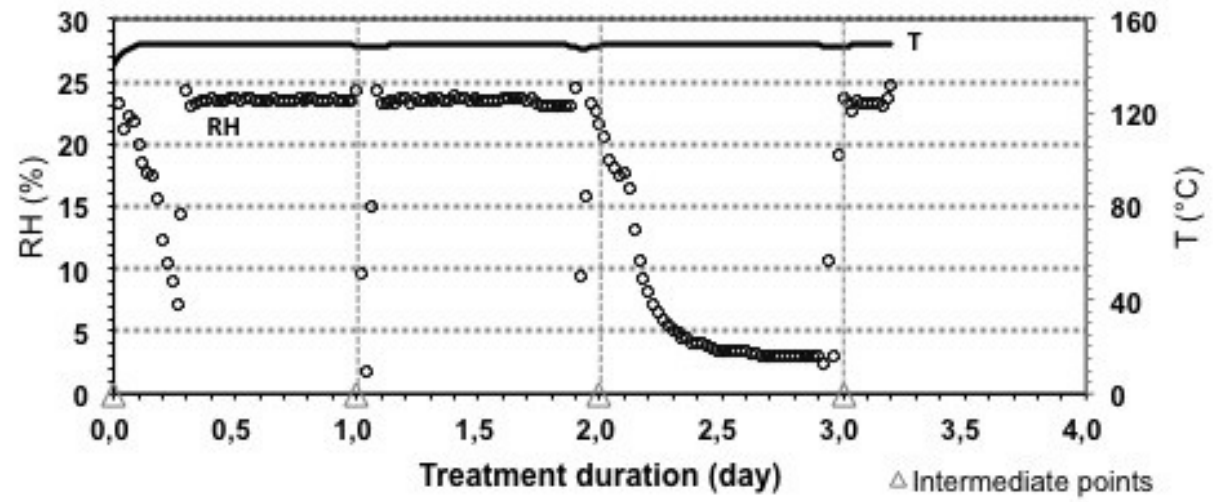

Fig. 2. Evolution of temperature and relative humidity during different treatment modalities: (a) $130^{\circ} \mathrm{C}$, treatment B; (b) $150^{\circ} \mathrm{C}$, treatment $\mathrm{D}$; (c) $150^{\circ} \mathrm{C}$, treatment $\mathrm{E}$. Intermediate points of measurement are indicated on the treatment duration axis 


\section{Physical properties}

Before, during and after treatments, mass and dimensions were measured for calculating oven-dry weight loss (WL), specific gravity (d), equilibrium moisture content (MC) and shrinkage (S). WL is calculated as eq.1:

$\mathrm{WL}(\%)=\frac{m_{0}^{u}-m_{0}^{t}}{m_{0}^{u}} \times 100$

where $m_{0}^{u}$ and $m_{0}^{t}$ are oven-dry mass of untreated and treated wood, respectively. Specific gravity (d) was calculated based on weight and dimension of specimens after stabilization in standard conditions eq.2:

$d=\frac{m}{V} / \rho_{H 2 O}$

where $m$ and $V$ are the mass and volume of the wood specimen and $\rho_{H 2 O}$ is the density of water. The equilibrium moisture content (EMC) is defined as eq.3:

$\operatorname{EMC}(\%)=\frac{m_{65 \%}-m_{0}}{m_{0}} \times 100$

where $\mathrm{m}$ is the mass of the wood (stabilized at $20^{\circ} \mathrm{C}$ and $65 \% \mathrm{RH}$ ) and mo is the oven-dry mass of wood. The (partial) dimensional shrinkage was assessed along the radial dimension of specimen's eq.4:

$S(\%)=\frac{l_{65 \%}-l_{0}}{l_{0}} \times 100$

where $l_{65 \%}$ is the dimension in stabilised condition and $l_{0}$ the oven-dry dimension.

\section{Vibration test}

Vibration tests were conducted on the principle of non-contact forced-released vibrations of freefree bars [22] (Obataya et al. 2000), using the experimental protocol and the device with computer interface described by [23; 24] Brémaud (2006), Brémaud et al. (2012). Damping coefficient (or internal friction) expressed as $\tan \delta$ was calculated as the inverse of the "quality factor" $Q$ or half-power bandwidth. The specific dynamic elastic modulus (E'/d) was deduced from the first resonance frequency according to Bernoulli equation (taking into account length and thickness of specimens). Vibrational properties were characterized both in the L (E' ${ }_{\mathrm{L}} / \mathrm{d}$ and $\left.\tan \delta_{L}\right)$ and $R\left(E_{R} / d\right.$ and $\left.\tan \delta_{R}\right)$ directions. Frequency range was $100-200 \mathrm{~Hz}$ for $\mathrm{R}$ specimens and $550-650 \mathrm{~Hz}$ for $\mathrm{L}$ ones.

\section{Colorimetric measurement}

Colour was measured with a spectrophotometer "spectra-guide sphere gloss" from BYK, type 6834, with a diameter of aperture of $10 \mathrm{~mm}$. Standard illuminant D65 and standard observer curve of $10^{\circ}$ were used. Data were collected in the CIELab system, were L* (lightness) is 0 for black, 100 for white, axis $a^{*}$ ranges from green $\left(-a^{*}\right)$ to magenta $\left(+a^{*}\right)$ and axis $b^{*}$ ranges from blue $\left(-b^{*}\right)$ to yellow $\left(+b^{*}\right)$. Data are also expressed in the more intuitive CIELCh system, eq.5:

$$
C^{*}=\sqrt{a^{* 2}+b^{* 2}}
$$


where $C^{*}$ is chromaticity (intensity of colour) and eq.6:

$h^{\circ}=\arctan \left(\frac{b^{*}}{a^{*}}\right)$

where $h^{\circ}$ is the hue angle.

\section{Reconditioning for studying recovery}

After all measurements, reconditioning has been performed to determine the reversible or irreversible effect of HTT. In Fig. 3, hygroscopic history of specimens is shown. Specimens were dried at $60^{\circ} \mathrm{C}$ for 48 hours and then at $103^{\circ}$ for 2 hours to reach anhydrous state. After oven drying, specimens have been stabilised ( 3 weeks for each step) in adsorption, at $20^{\circ} \mathrm{C}$ and $65 \%$ RH first (point 1 in Fig. 2), then at $90 \%$ RH. This was followed by desorption from $90 \%$ to $65 \%$ and from $65 \%$ to $0 \% \mathrm{RH}$. At the end, to compare with the first step after treatment, an adsorption was applied from $0 \%$ to $65 \% \mathrm{RH}$ for 3 weeks (point 3 in fig.2). After each step, weight and dimension were measured and EMC and density have been calculated. After stabilization at $65 \%$ $\mathrm{RH}$, vibration properties were also measured.

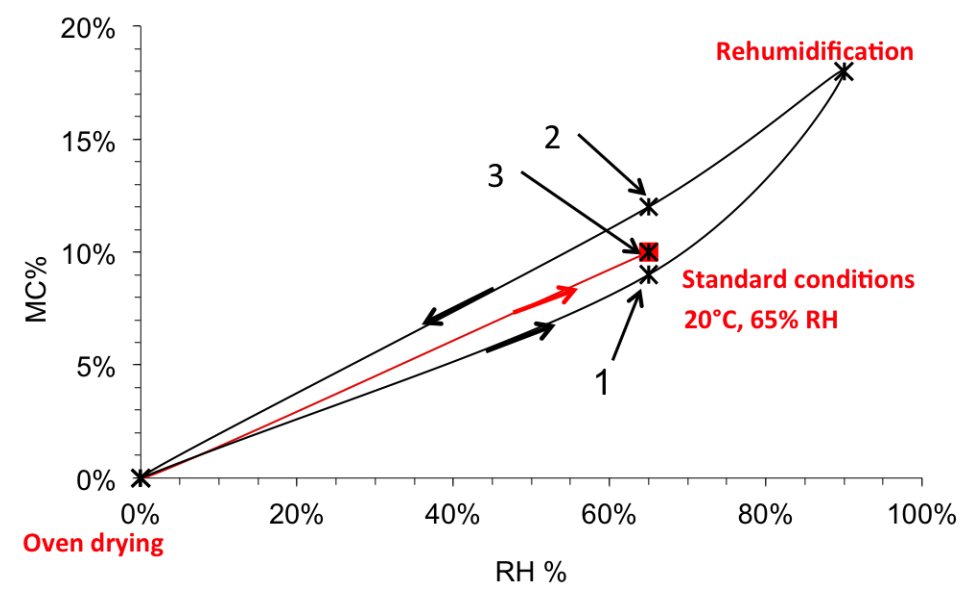

Fig. 3. Reconditioning from the first point of stabilisation after treatment at standard conditions (1), until a complete cycle of humidity (3)

\section{Results and discussions}

\section{Kinetics of modification during treatments monitored by colorimetry}

The kinetics of modification was monitored during treatment through oven-dry weight and colorimetry. In the absence of treatment, the colorimetric values measured on air-dry or anhydrous wood are not much different for lightness $(-1 \%)$, but oven-dry wood appears less saturated $\left(\Delta \mathrm{C}^{*}=-9 \%\right)$ and more "yellow" $\left(\Delta \mathrm{h}^{\circ}=+7 \%\right)$. The change of colour lightness $\left(\mathrm{L}^{*}\right)$, as measured on oven-dry wood, is presented in Fig. 4 as a function of treatment duration for the different treatment conditions. As expected, L* decreases along with treatment duration. The decrease is clearly enhanced by higher temperature of treatment (after 7 days in dried condition, $\mathrm{L}^{*}$ is reduced by $20 \%$ when treated at $130^{\circ} \mathrm{C}$, while $\mathrm{L}^{*}$ is reduced by $41 \%$ when treated at $150^{\circ} \mathrm{C}$ ). For the same temperature, the decrease of $\mathrm{L}^{*}$ is smaller by treatment at $0 \% \mathrm{RH}$ than by 
treatment at variable RH. It seems that a variation in treatment humidity induces a larger effect on $\mathrm{L}^{*}$.

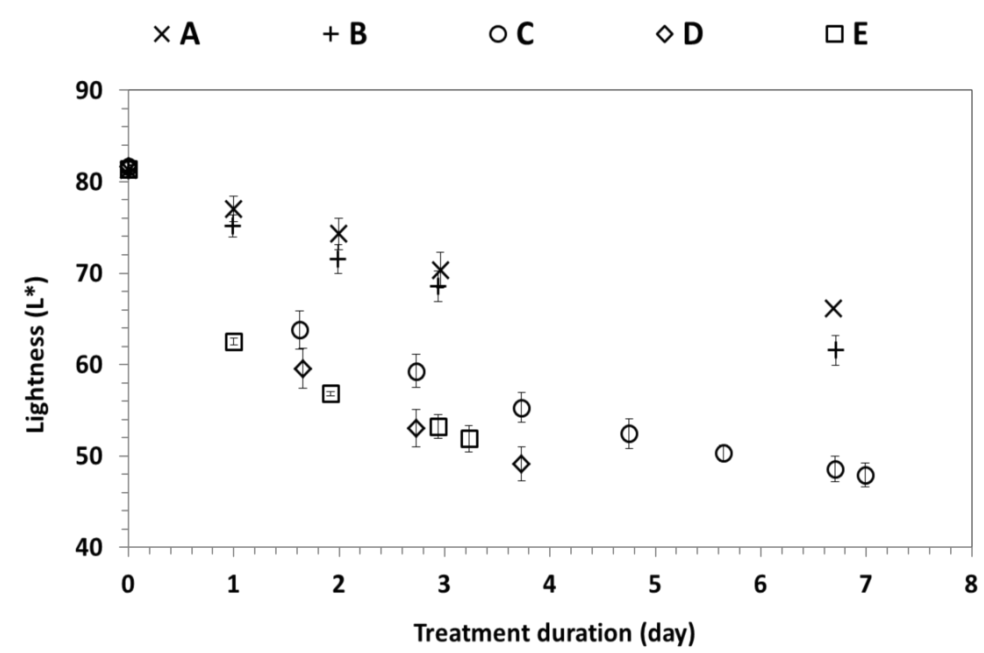

Fig. 4. Evolution of colour lightness L versus treatment duration

The other colorimetric parameters ("redness" a*, "yellowness" b* and the more synthetic parameters chromaticity $\mathrm{C}^{*}$ and hue $\mathrm{h}^{\circ}$ ) are necessary to describe the perception of colour. Furthermore, in previous studies, different trends of changes are found for $\mathrm{a}^{*}$ and $\mathrm{b}^{*}$ along time of aging and/or temperature and time of thermal treatment [30] (Matsuo et al. 2011). However, in the case of mild temperatures as applied in the present work, all changes in $\mathrm{C}^{*}$ and $\mathrm{h}^{*}$ due to the different durations and modalities of HTT appear to follow a single trend in relation to the changes in $\mathrm{L}^{*}$ (Fig. 5). As $\mathrm{C}^{*}$ and $\mathrm{h}^{\circ}$ represent, respectively, the "amount of colour", and the "ratio of redness to yellowness", these two parameters provide a more precise view of changes in colour than parameters $\mathrm{a}^{*}$ and $\mathrm{b}^{*}$ separately. The hue angle $\mathrm{h}^{\circ}$ decreases almost linearly along with lightness $\mathrm{L}^{*}$, that is, the darker the treated wood becomes, the redder (Fig. 5b). Regarding the "amount of colour" or chromaticity $\mathrm{C}^{*}$, it increases when $\mathrm{L}^{*}$ decreases from circa 85 to 60 , then decreases when $\mathrm{L}^{*}$ further decreases below values of circa 60 (Fig. 5a). This non-linearity is not an effect of thermal treatment: it is generally observed when comparing untreated wood from many different species [25; 23] (Nishino et al. 1998; Brémaud 2006), and simply reveals some characteristics of the CIELab colour space. In summary, in the present work, $L^{*}$ appears to be a sufficient descriptor of colour changes: it is very sensitive to the different modalities of treatments, while being the only "linear" parameter in the CIELab space, and it is also closely correlated to weight loss due to HTT (Fig. 6). 

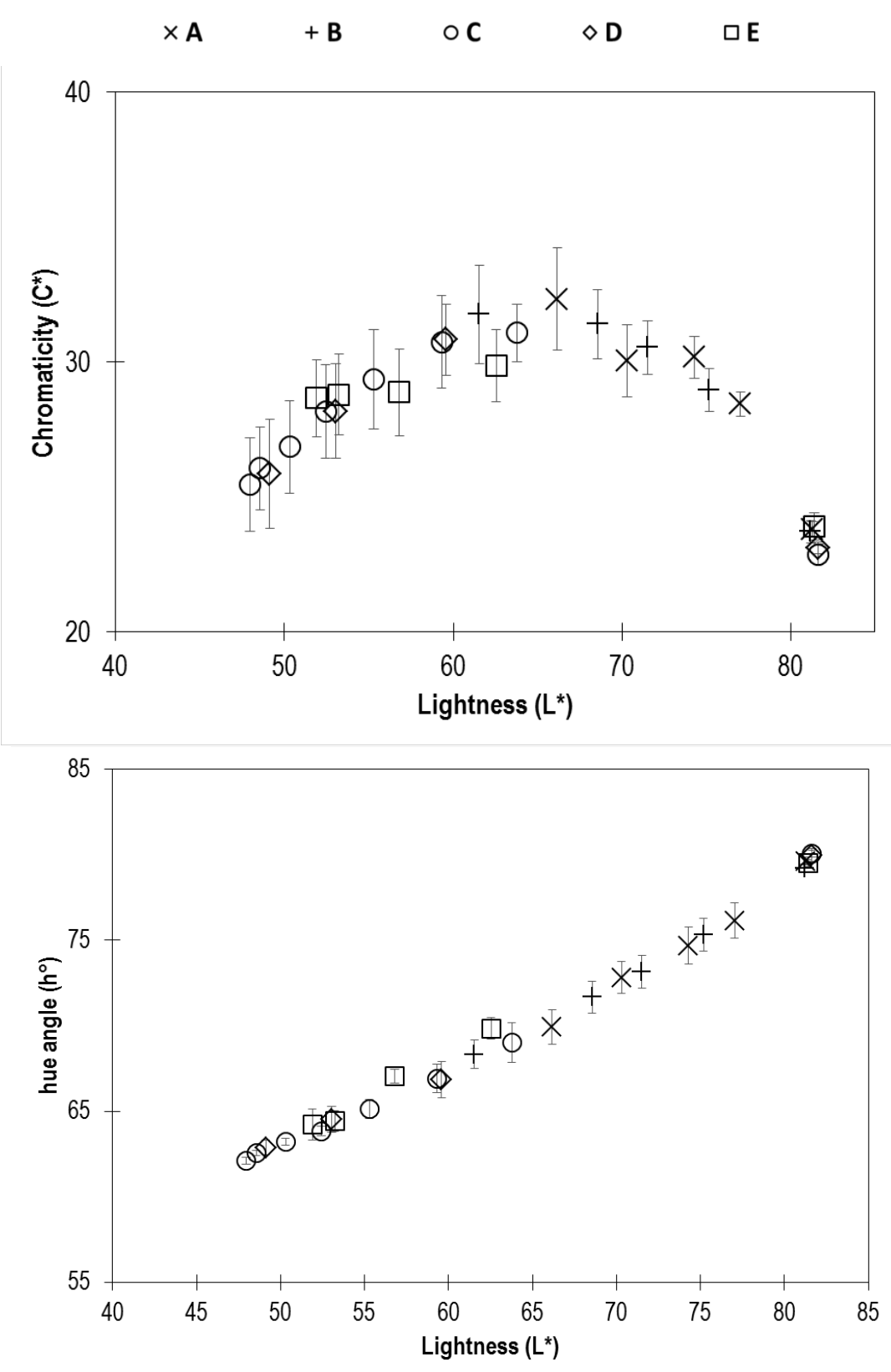

Fig. 5. The changes in colorimetric parameters (a) chromaticity $C^{*}$ and (b) hue angle $\mathrm{h}^{\circ}$ as related to changes in colour lightness $\mathrm{L}^{*}$, along the different durations and modalities of treatment.

\section{Changes in properties after complete treatment}

After completion of the mild treatments applied, WL remained small, ranging from $0 \%$ to $4 \%$ (Fig. 6), indicating very little loss of components. However, the colour lightness L* was clearly reduced (even for a nearly $0 \% \mathrm{WL}$ ), indicating some chemical modification [12] (Endo et al., 2015). The decrease in $L^{*}$ was closely connected to increasing WL, suggesting $L^{*}$ to be a good indicator of the intensity of thermal treatment. The equilibrium moisture content (EMC) was also clearly decreases (even for nearly null WL), its decrease was also quite closely related 
to WL. Changes in EMC may indicate both some chemical changes [6] (Obataya et Tomita, 2002), or some physical changes able to reduce hygroscopicity [14] (Obataya et al., 2000).

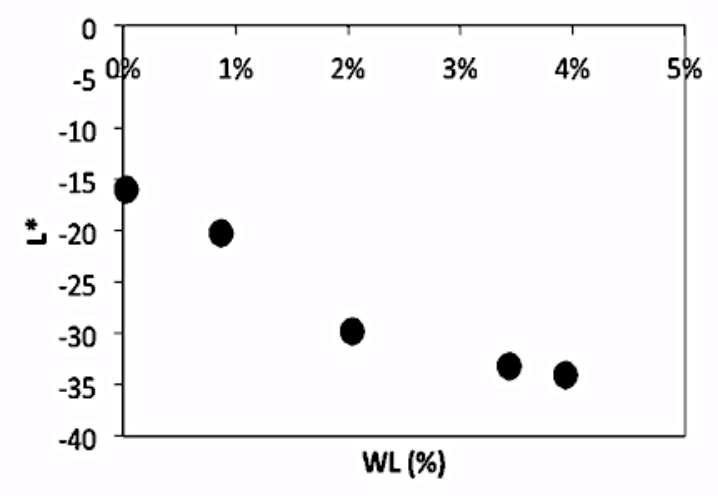

a

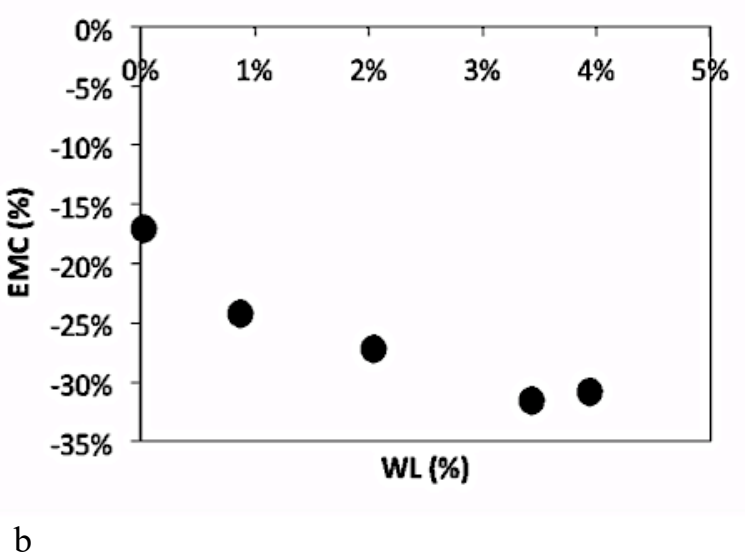

Fig. 6. Evaluation of weight loss (WL) against lightness $L^{*}$ (a) and equilibrium moisture content EMC (b) at the end of treatments (for treatment A, B, C, D and E)

Average values of physical (d, EMC), vibrational (E'/d and tan $\delta$ in $\mathrm{L}$ and $\mathrm{R}$ directions) and colorimetric $\left(\mathrm{L}^{*}, \mathrm{C}^{*}, \mathrm{~h}^{*}\right)$ properties, after complete treatment, are compared in Table 2 between control groups and specimens that underwent HTT. Incidentally, for control groups, the effect of drying mainly resulted in a decrease in subsequent EMC (by 11\% relative change, that is, from 12.4 to $10.9 \%$ EMC in absolute values), with only minor changes in other properties ( $\leq 1 \%$ for density and specific modulus of elasticity, $\leq 3 \%$ for damping). The final values of EMC and $\mathrm{d}$ after complete treatment are reduced, compared to control groups, and duration and temperature of HTT influence this effect: a larger decrease is observed for longer duration and higher temperature. HTT is accompanied by a weight loss enhanced by longer duration and higher temperature. Regarding mechanical properties, specific modulus $\mathrm{E}_{\mathrm{L}} / \mathrm{d}$ and $\mathrm{E}_{\mathrm{R}} / \mathrm{d}$ are increased after HTT whereas $\tan \delta_{\mathrm{L}}$ and $\tan \delta_{\mathrm{R}}$ are reduced.

Table 2. Physical, vibrational and colorimetric properties of treated groups (for treatment A, B, C, D, E) and of the control group of specimens.

\begin{tabular}{ccccccccccc}
\hline Treatment & $\boldsymbol{d}$ & $\begin{array}{c}\mathbf{E M C} \\
\mathbf{( \% )}\end{array}$ & $\begin{array}{c}\boldsymbol{E}^{\prime}{ }_{\mathbf{L}} / \boldsymbol{d} \\
\mathbf{G P a})\end{array}$ & $\begin{array}{c}\boldsymbol{E}^{\prime}{ }_{\boldsymbol{R}} / \boldsymbol{d} \\
\mathbf{G P a})\end{array}$ & $\boldsymbol{\operatorname { t a n } \boldsymbol { \delta } _ { \mathbf { L } }}$ & $\boldsymbol{\operatorname { t a n } \boldsymbol { \delta } _ { \mathbf { R } }}$ & $\mathbf{L}^{*}$ & $\mathbf{C}^{*}$ & $\mathbf{h}^{\circ}$ & $\mathbf{W L}(\mathbf{\%})$ \\
\hline $\mathbf{A}$ & 0,462 & 9,0 & 33,9 & 1,48 & 0,0057 & 0,0179 & 65,75 & 32,22 & 70,24 & 0,51 \\
$\mathbf{B}$ & 0,455 & 8,1 & 33,7 & 1,50 & 0,0053 & 0,0169 & 61,57 & 32,23 & 68,53 & 1,35 \\
$\mathbf{C}$ & 0,449 & 7,3 & 31,4 & 1,45 & 0,0056 & 0,0157 & 48,19 & 25,80 & 62,46 & 4,42 \\
$\mathbf{D}$ & 0,448 & 7,2 & 32,6 & 1,51 & 0,0055 & 0,0153 & 48,82 & 26,25 & 62,85 & 3,91 \\
$\mathbf{E}$ & 0,455 & 7,7 & 33,7 & 1,47 & 0,0054 & 0,0164 & 51,99 & 28,86 & 64,33 & 2,52 \\
Control & 0,465 & 10,9 & 32,6 & 1,42 & 0,0059 & 0,0220 & 81,86 & 23,91 & 79,83 & $-0,48 \%$ \\
\hline
\end{tabular}

To analyse more precisely these effects, variations of each property are calculated between treated and untreated specimens, and then these variations are corrected by subtracting the variations for the same property for control specimens, this will be called "relative change".

In Fig. 7, the relative changes in physical properties are compared between the different treatment modalities. Higher temperature obviously accelerates the processes. Varying humidity conditions also appear to accelerate the process, although, as can be seen in Fig. 4, the fact that 
this modality was run for only half the duration of treatment $\mathrm{D}$ at $150^{\circ} \mathrm{C}$, partly masks the final effects in Fig. 7. The decrease in EMC is closely followed by a decrease in radial partial shrinkage (S). When comparing the effects of different modalities of treatment on vibration properties, the same trends can be observed. Damping coefficient in L direction was remarkably decreased (by as much as $-30 \%$ ), also decreased in L but with smaller amplitude (1/3 or variations as compared to $\mathrm{R}$ ). Properties in radial direction are significantly more affected than those in axial direction, thus leading to a reduction in anisotropy. It was already reported that up to now, most treatments able to reduce damping involve a reduction in anisotropy $[14 ; 13]$ (Obataya et al. 2000, Noguchi et al. 2012). For specific modulus of elasticity, treatments induced an increase (up to $8 \%$ ) in $\mathrm{R}$ direction, while there was no obvious effect of treatment in $\mathrm{L}$ direction.
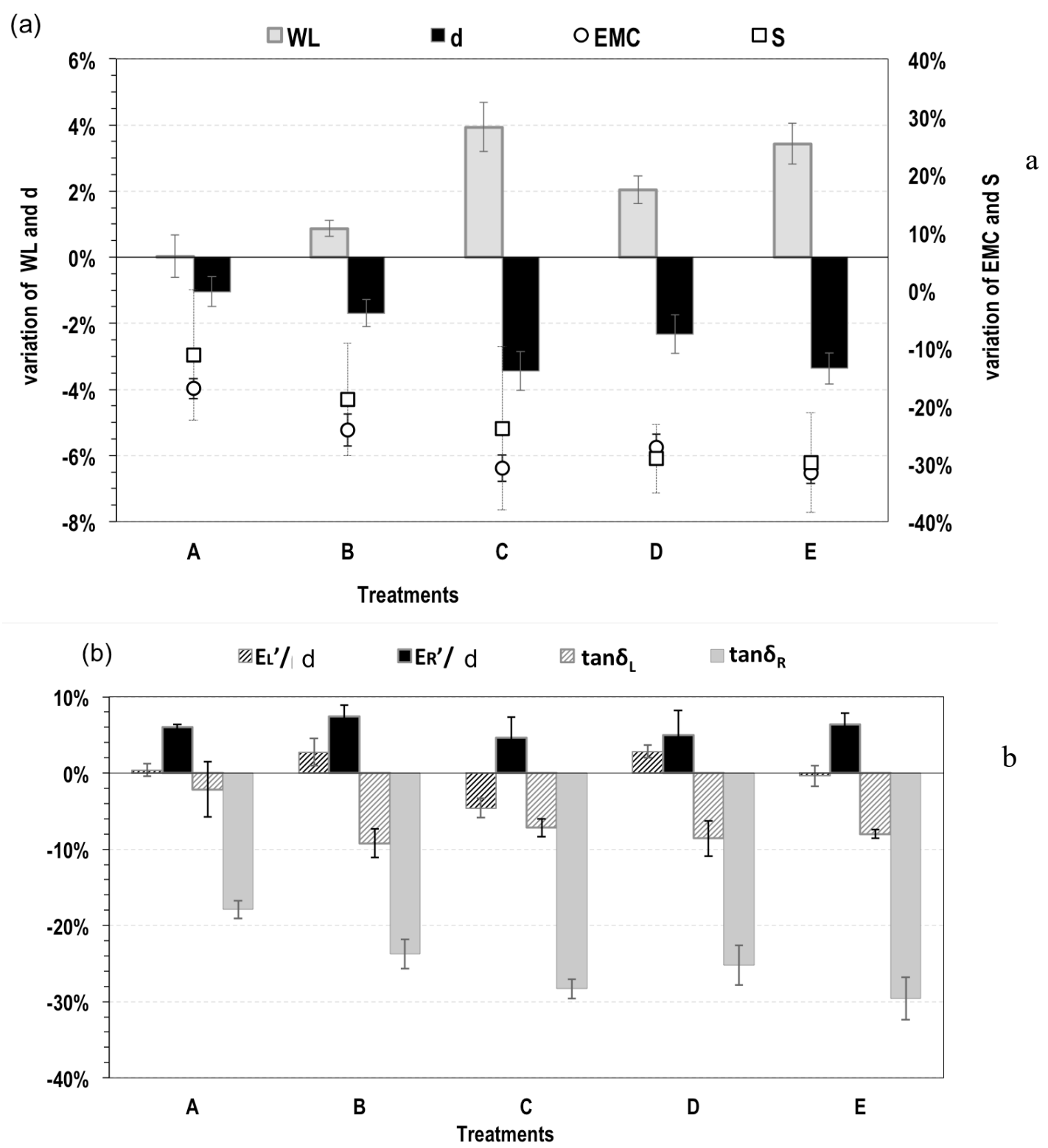

Fig. 7. Relative changes of properties after completion of the different hygrothermal treatment procedures. (a) Physical properties (WL, d, EMC and S); (b) vibration properties (in axial and radial directions) after completion of the different hygrothermal treatment procedures. 
When analysing the correlations between the amplitudes of relative changes in the different measured properties, it can be deduced that WL is a good indicator of changes in EMC and in lightness $\mathrm{L}^{*}$ (Fig. 6), but not so for changes in vibrational properties. Changes in vibrational properties are much better correlated with changes in colour $\left(\mathrm{L}^{*}\right.$ and $\left.\mathrm{h}^{\circ}\right)$. This suggests that vibrational properties are affected by chemical changes, but not to changes/degradations leading to loss of material. [14; 6] (Obataya et al., 2000; Obataya and Tomita, 2002). Finally, changes in damping are better correlated with changes in EMC or with $\mathrm{L}^{*}$ and $\mathrm{h}^{\circ}$ than with changes in elastic modulus. As tan $\delta$ has normally a very strong correlation with E'/d [14; 24] (Obataya et al 2000, Brémaud et al 2012), and given that WL is very low, these observed effects on both colour, EMC and damping are rather reminiscent of what could be observed in the case of the role of extractives [26] (Brémaud et al 2010).

By applying a higher temperature, E'/d will decrease remarkably and tan $\delta$ increase with increasing WL [15] (Obataya, 2017). This could be because of the depolymerisation of hemicelluloses into water-soluble components, which has the role of a plasticizer in the cell wall [27] (Zauer et al., 2016). Hemicelluloses is the most important component to maintain the fiberreinforced structure of wood cell wall [28] (Akerholm et Salmen, 2001) while its depolymerisation cause producing low-molecular-weight sugars which can be considered as the reason for increasing tan $\delta$ by more intense treatment [31] (Obataya et Norimoto, 1999)

In the case of the mild treatments applied here, the small weight loss, together with no reduction in specific modulus (or instead an increase in $\mathrm{R}$ direction), suggest that are indeed some chemical modifications (clearly shown by changes in colour), but very little loss of material/degradation. The important effects on tan $\delta$ and on EMC suggest some changes in configuration of molecules [15] (Obataya, 2017).

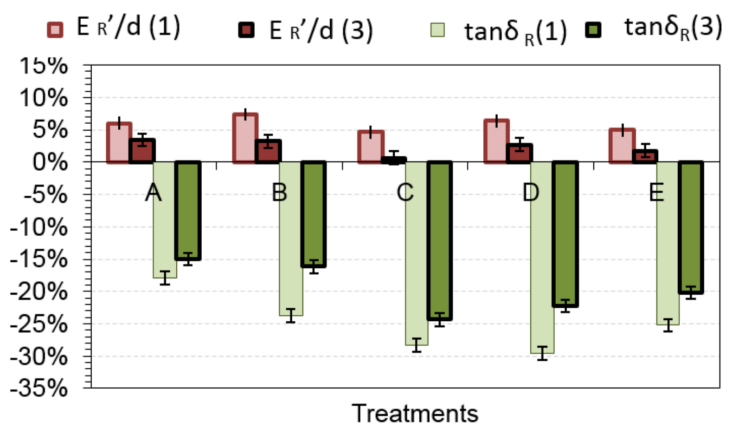




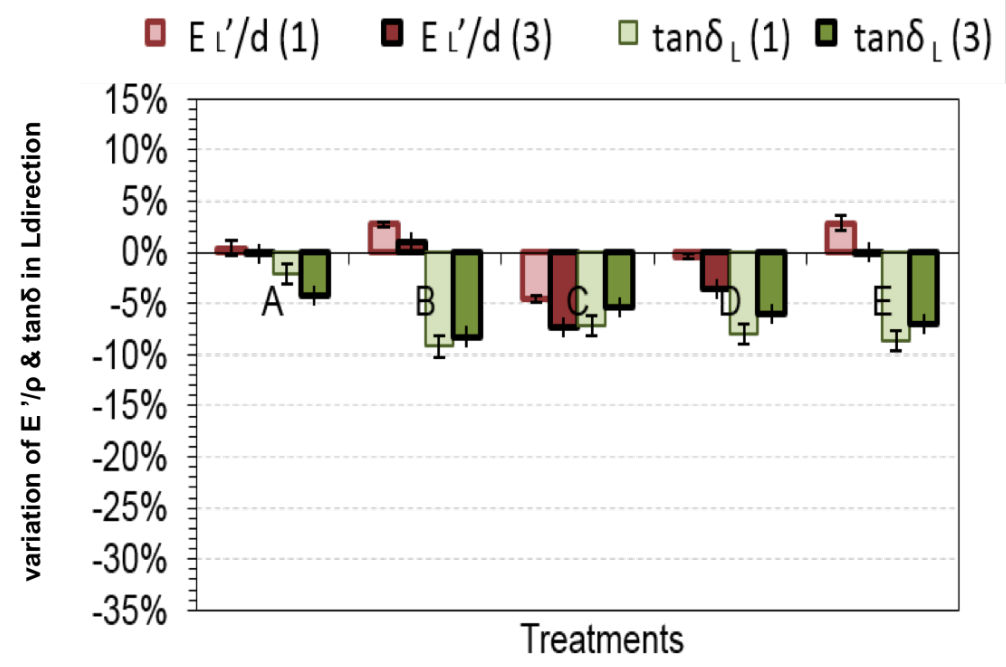

Fig. 8. Variations of relative changes of vibration properties after reconditioning between point 1 and 3 (a) $\mathrm{R}$ direction and (b) $\mathrm{L}$ direction.

\section{Partial recovery by reconditioning}

Fig.8 (a,b) shows how vibrational properties where affected after hygrothermal treatment (1) and then after reconditioning (3). For R direction, a clear part of initial changes is recovered after reconditioning both for damping and for modulus. It means that some parts of changes due to HTT are reversible. Changes in tan $\delta$ are up to $7 \%$ less important than initially observed after HTT. The biggest effect has been found for the strongest treatments at $150^{\circ} \mathrm{C}$ and variable $\mathrm{RH}$ (D). For modulus, reconditioning induced an obvious re-decrease following the initially observed increases for all treatments. In L direction, the trends were the same (the relative changes in properties observed just after HTT were re-decreased after reconditioning) except for modulus in $\mathrm{L}$ direction, given that the initial effect of HTT was not clear in this direction.

In Fig. $9(a, b)$ the changes due to reconditioning Vs. those of initial effects of HTT in partial shrinkage S (a) and specific gravity d (b) is shown against the "recovery" in EMC. In Fig.8 b, after reconditioning, a clearly lower diminution from untreated wood (compared to initial HTT changes) of EMC is followed by similar trend for specific gravity. It is logistical that a decrease in moisture content of wood results in a decrease of "air-dry" specific gravity. In Fig. $8 \mathrm{a}$, the same trend can be seen between EMC and S (partial shrinkage). With decrease in moisture content, the shrinkage will decrease because the capacity of wood to adsorb and desorb water is decreased. After reconditioning, parts of the initially observed decrease in EMC and in S are recovered. These partial recoveries can be seen for all the treatments. For specific modulus of elasticity, the initial effect of HTT is partially recovered by reconditioning (Fig. 9c-d). In R direction, initially observed increase after HTT is reduced or become null (Fig. 9d), while in L direction it is either completely recovered by reconditioning (Fig. 9c), of even, decreases in E/d appear for the strongest treatments after recovery. For damping in R direction, the same recovery trend is clear; the initially induced changes are recovered following the recovery in EMC. While in $\mathrm{L}$ direction the recovery is small, because initial changes were small (Fig. 9e-f). 


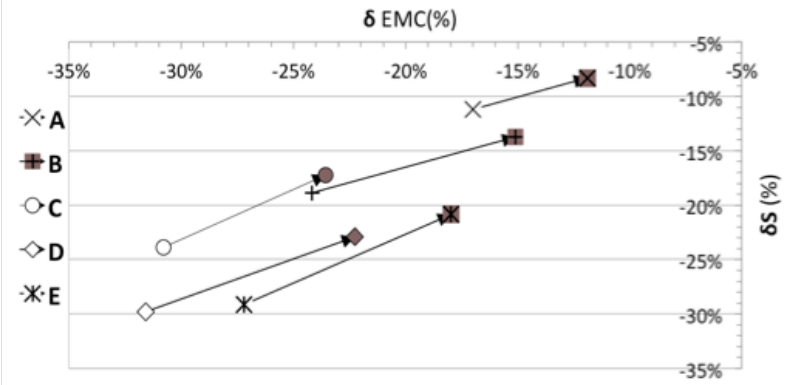

a

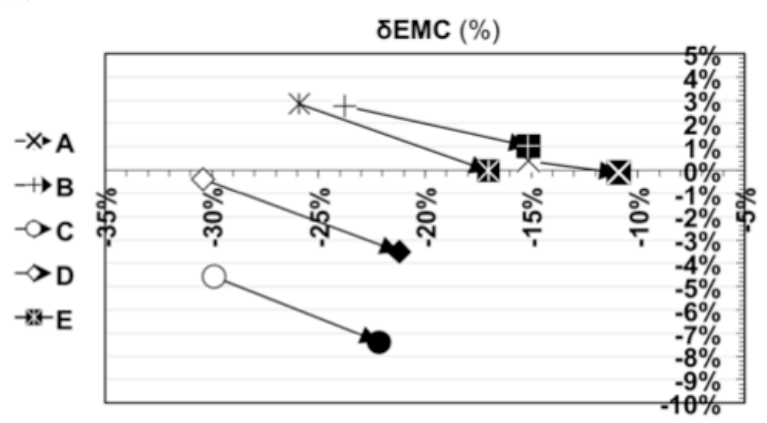

C

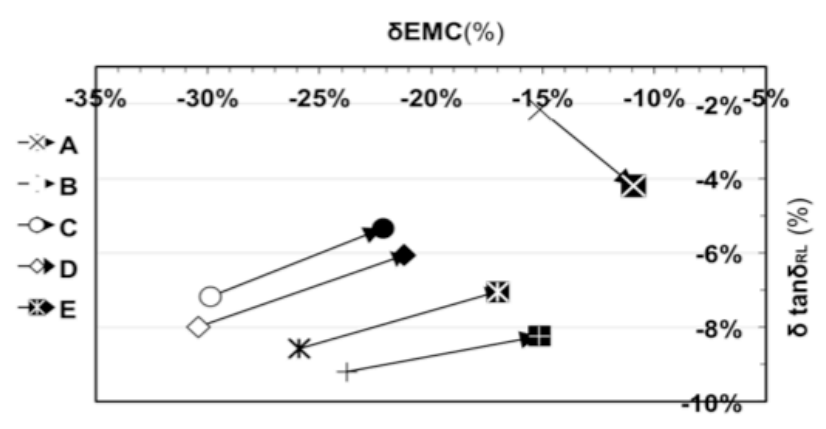

e
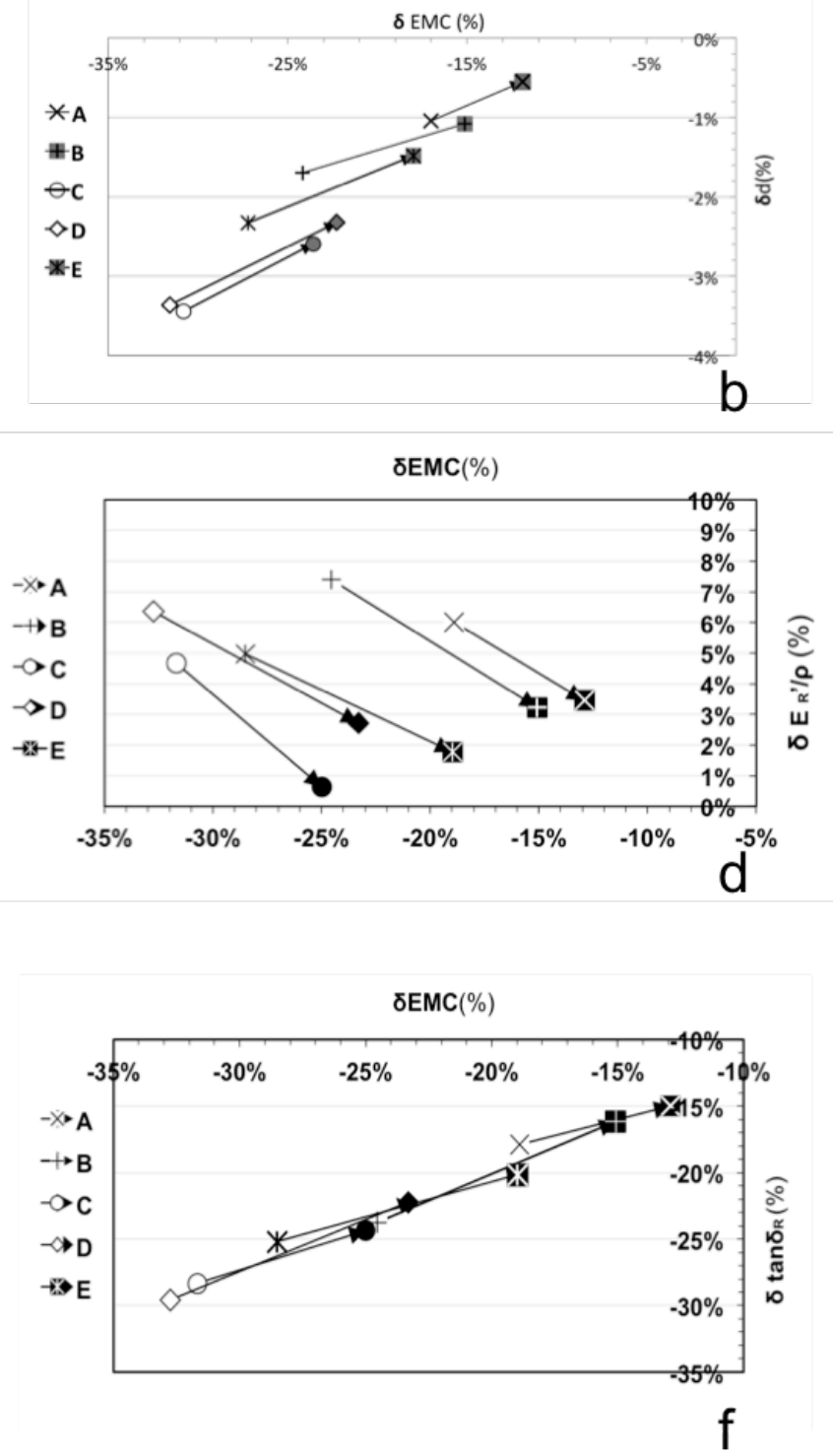

Fig. 9. Correlations between variations of relative changes of EMC and others properties after reconditioning (a) EMC vs S; (b) EMC vs d; (c) EMC vs E ${ }_{\mathrm{R}} / \mathrm{d}$; (d) EMC vs E' ${ }_{\mathrm{L}} / \mathrm{d}$; (e) EMC vs $\tan \delta_{\mathrm{R}}$; (f) EMC vs $\tan \delta_{\mathrm{L}}$. Empty symbols correspond to values after treatment; bold symbols correspond to values after reconditioning.

\section{Results and discussion of reversibility of HTT}

During hygrothermal treatment WL could be changed depending on treatment conditions (Temperature, humidity, etc.) and can be an indicator for treatment intensity. In this study, the small WL resulted from the mild hygrothermal treatment; indicate that little material was removed from the wood structure.

Also, color of HTT of wood represents a significant change. As the colour is evaluated by Lightness ( $\mathrm{L}^{*}$ ), the changes in $\mathrm{L}^{*}$ have been plotted against WL (Fig. 6). There is an decrease in $\mathrm{L}^{*}$ of treated wood while the weight loss increase. As the color parameters of HTT wood are 
connected to WL, it can be deduced that color changes and WL are affected by the same chemical reaction [12] (Endo et al., 2016).

HTT by intermediate relative humidity ( $80 \%$ or less) causes partially reversible changes and less WL [6] (Obataya and Tomita, 2002), while irreversible effects of HTT and in addition more WL are suspected in the case of high relative humidity (90\%) [12] (Endo et al., 2016).

In the present study, low WL in the presence of intermediate RH (25\% or lower) coincides with decrease in EMC. An Investigation has been performed to find the effects of humidity on physical properties of hygrothermally treated spruce [12] (Endo et al., 2016). They have indicated by intermediate heating humidity, the WL is less and thereafter the EMC changes less than using high humidity. They also mentioned that change in properties by heating in intermediate relative humidity is partly reversible and are possibly due to the physical ageing or annealing of wood polymers. Also, [15] Obataya (2007) investigated that reversible reduction of hygroscopicity could be due to the physical ageing or annealing of amorphous polymers. In this study the same result has been found while by moistening of treated wood, changes in EMC was partly reversible which could be attributed to the physical ageing of wood polymers.

It has to be considered that after moistening, partly recovery has been observed. Whereas, after moistening vibrational properties (such as $\tan \delta_{\mathrm{R}}$ and $\tan \delta_{\mathrm{L}}$ ) remain mostly irreversible $(-10$ to $-25 \%$ for $\tan \delta \mathrm{L},-4$ to $-8 \%$ for $\left.\tan \delta_{\mathrm{R}}\right)$. The vibrational properties of hygrothermally treated spruce has investigated and the results stated that mild hygrothermally treatment with intermediate relative humidity can improve the acoustic quality of wood by decreasing tan $\delta$ and increasing $\mathrm{E} \% \mathrm{~d}$. while, the changes in properties remain unchanged after a partially recovery [15] Obataya (2017). Also, suggested that thermal treatment at low moisture content has a little effect on molecular motions of amorphous cell wall substances that resulted in unrecoverable changes in vibrational properties [6] Obataya et al (2000). Also, they have mentioned that irreversible reduction in hygroscopicity is because of the chemical changes of amorphous polymers but not for the recrystallization of celluloses.

As before mentioned, irreversible changes of HTT are suspected to be related to chemical changes. These chemical changes such as loss of extractives and hygroscopic hemicelluloses, crystallization of celluloses and cross-linking of lignin [12] (Endo et al., 2016). These chemical changes led to weigh loss during treatment.

The degradation of the most affected component in wood, hemicellulose resulted in the composition of acetic acid, which plays as a catalyser and causes degradation of polysaccharides. This change coincides with the dehydration reaction of hemicelluloses with decrease in hydroxyl groups [29] (Esteves et Pereira, 2009). So, less water can be absorbed by the cell walls because of the decrease in hydroxyl groups, which led to the decrease in EMC.

In this study, Irreversible changes in vibrational properties can be attributed to the chemical changes. The irreversible reduction of EMC and colour, which are coinciding with the increasing WL, can be due to the chemical changes. But suggested chemical changes coincide with not significant WL and no obvious damage by mild HTT.

\section{Conclusion}

1. In this study mild hygrothermal treatment causes changes in EMC, colour, weight and vibrational properties such as tan $\delta$ and E'/d. For all the treatments, WL was very low and not significant (maximum 4\%) while colour decreased significantly.

2. As well as, reduction has been found for the EMC. After the reconditioning, partially recovery has been resulted for EMC, and vibrational properties. However, there are still 
changes due to the HTT for EMC and vibrational properties of treated wood. It has been suggested that partially recovery for mild HTT and intermediate treatment humidity could be suspected to the physical ageing and annealing of amorphous wood polymers.

3. On the other hand, chemical changes in wood composition such as hydrolysis and depolymerisation of hemicelluloses, crystallisation of celluloses and cross-linking of lignin are suggested to be the reason of irreversible changes in physical and vibrational properties. Since, mild hygrothermal treatment has been applied in the intermediate relative humidity, improvement in vibrational properties by increasing in $E$ '/d and decreasing in $\tan \delta$ remains partially unrecoverable. Therefore, acoustical improvement has been resulted by mild hygrothermal treatment. It is necessary to mention that applied mild hygrothermal treatment causes improved EMC and vibrational properties, even after recovery coincides with no significant WL and no obvious damage in treated wood. Further investigations are necessary to test these hypotheses.

\section{Acknowledgements:}

The authors are pleased to acknowledge the help of Prof. Parviz Navi and Dr. Julien Froidevaux of Bern University of Applied Science, for performing the thermal treatments through a visit made possible by a Germaine de Stael funding between France and Switzerland in 2011, and the support of CIRAD for performing measurements. Also, the authors are grateful for the supporting and funding of the thesis of Elham Karami by Campus France and Embassy of France in Iran. The authors are grateful for the support of "Advanced research supporting the forestry and wood-processing sector's adaptation to global change and the 4th industrial revolution", No. CZ.02.1.01/0.0/0.0/16_019/0000803 financed by OP RDE"

\section{References:}

[1] Kollmann F (1936) Technologie des Holzes - Erster Band Julius Springer Verlag Berlin.

[2] Stamm AJ, Hansen L.A (1937) Minimizing Wood Shrinkage and Swelling Effect of Heating in Various Gases. Ind. Eng. Chem.1937297831-833

[3] Kollmann F, Schneider A (1963) On the sorption behavior of heat stabilizied wood, Holz Roh-Werkst, 21(3): 77-85.

[4] Kollmann F, Fengel D (1965) Changes in the chemical composition of wood by heat treatment, Holz Roh-Werkst. 12: 461-468.

[5] Militz H (2002) Heat treatment of wood: European processes and their background. In: International Research Group Wood Pre, section 4-Processes, N IRG/WP 0240241.

[6] Obataya E, Tomita B (2002) Hygroscopicity of heat-treated wood. II Reversible and irreversible reductions in the hygroscopicity of wood due to heating. Mokuzai Gakkaishi 48:288-295

[7] Tjeerdsma B, Militz H (2005) Chemical changes in hydroheat wood: FTIR analysis of combined hydroheat and dry heat-treated wood. Holz Roh-Werkst. 63: 102-111. 
[8] Hill C (2006) Wood Modification Chemical, thermal and other processes. Wiley, New York, , ISBN: 0-470-02172-1, pp 239.

[9] Boonstra M (2008) 1two-stage thermal modification of wood Ph.D. Thesis in applied biological sciences: Soil and Forest management, Henry Poincare' University-Nancy, France.

[10] Matsuo, M., Yokoyama, M., Umemura, K., Gril, J., Yano, K. I., \& Kawai, S. (2010). Color changes in wood during heating: kinetic analysis by applying a time-temperature superposition method. Applied physics A, 99(1), 47-52.

[11] Sandberg D, Navi P (2013) Thermo-hydro and thermo-hydro-mechanical wood processing: an opportunity for future environmentally friendly wood products, Wood Mat. Sci. Eng. 8:64-88.

[12] Endo K, Maejima H, Obataya E (2015) Hygroscopicity and vibrational properties of hydrothermally treated wood, Abstracts of the International Symposium on Wood Science and Technology, Tokyo, Japan, 1WP-P05.

[13] Noguchi T, Obataya E, Ando K (2012) Effect of aging on the vibrational properties of wood. Journal of Cultural Heritage 13:S21-S25.

[14] Obataya E, Tanaka F, Norimoto M, Tomita B (2000) Hygroscopicity of heat-treated wood Effects of after-treatments on the hygroscopicity of heat-treated wood. Mokuzai Gak-kaishi 46:77-87.

[15] Obataya E (2017) Effects of natural and artificial ageing on the physical and acoustic properties of wood in musical instruments, Journal of Cultural Heritage, Volume 27, Supplement, October 2017, pp S63-S69.

[16] Pfriem A (2015) Thermally Modified Wood for Use in Musical Instruments. September, Drvna Industrija 66(3):251-253.

[17] Kubojima Y, Okano T, Ohta M (1998) Vibrational properties of sitka spruce heat-treated in nitrogen gas. J. Wood Sci. 44:73- 77.

[18] Assor C, Placet V, Chabbert B, Habrant A, Lapierre C, Pollet B, \& Perre P (2009) Concomitant changes in viscoelastic properties and amorphous polymers during the hydrothermal treatment of hardwood and softwood. Journal of Agricultural and Food Chemistry, 57(15): 6830-6837.

[19] Froidevaux J (2012) Wood and paint layers aging and risk analysis of ancient panel painting. PhD thesis, University Montpellier 2.

[20] Obataya E, Norimoto M, Gril J (1998) the effects of adsorbed water on dynamic mechanical properties of wood. Polymer 29:3059-3064.

[21] Brémaud I, Gril J (2015) Effect of transitional moisture change on the vibrational properties of violin-making wood. 3rd Conference of COST Action FP1302 WoodMusICK "Effects of playing on early or modern musical instruments", 9-10 September 2015, London, UK, pp 2.

[22] Obataya E, Ono T, Norimoto M (2000) Vibrational properties of wood along the grain. Journal of Materials Sciences 35: 2993-3001.

[23] Brémaud I (2006) Diversité des bois utilisés ou utilisables en facture d'instruments de musique. -Etude expérimentale des propriétés vibratoires en direction axiale de types de bois contrastés en majorité tropicaux. -Relations à des déterminants de microstructure et de composition chimique secondaire. Doctorat Mécanique, Université Montpellier II, pp 302.

[24] Brémaud I, El Kaïm Y, Guibal D, Minato K, Thibaut B, Gril J (2012) Characterisation and categorisation of the diversity in viscoelastic vibrational properties between 98 wood types. Annals of Forest Science 69: 373-386. 
[25] Nishino Y, Janin G, Chanson B, Détienne P, Gril J \& Thibaut B, (1998) Colorimetry of wood specimens from French Guiana, Journal of Wood Science volume 44, pages3-8(1998)

[26] Brémaud I, Minato K, Langbour P, Thibaut B (2010) Physico-chemical indicators of the inter-specific variability in vibration damping of wood. Ann For Sci 67: 707.

[27] Zauer M, Kowalewski A, Sproßmann R, Stonjek H, Wagenführ A (2016) Thermal modification of European beech at relatively mild temperatures for the use in electric bass guitars. European Journal of Wood and Wood Products, 74 (1): 43-48.

[28] Akerholm M, Salmen A (2001) Interactions between wood polymers studied by dynamic FT-IR spectroscopy. Polymer 42(3): 963-969.

[30] Matsuo M, Yokoyama M, Umemura K, Sugiyama J, Kawai S, Gril J et al (2011) Aging of wood: analysis of color changes during natural aging and heat treatment. Holzforschung, 65(3): 361-368.

[31] Obataya E, Norimoto M (1999) Mechanical relaxation process due to sugars in cane (Arundo donax L.). Wood Sci, 45: 378-383. 